\title{
Correlation between Students' Cognitive Reading Strategies and Reading Comprehension
}

\section{Edi Wahyono}

Universitas Cokroaminoto Palopo

ediwh2018@gmail.com

\begin{abstract}
This research aims to 1) describe students' responses toward cognitive reading strategies and their reading comprehension score; 2) find out the correlation between students' cognitive reading strategies and their reading comprehension. The current research is quantitative in nature. The quantitative is intended to describe the responses of students to cognitive and reading strategies and to explain to what extent the correlation between students' cognitive reading strategies and reading comprehension. The samples are the fourth semester students of English education as subjects or participants of the research. Data were collected by distributing questionnaires to get responses from students in term of Cognitive Reading Strategies. IELTS Reading Testing was used to get Students' reading comprehension scores. The quantitative data were analyzed by correlation product moment. The results of the study shows that most of students usually use four cognitive reading strategies included in this research and cognitive reading strategies correlate significantly to students' reading comprehension with $p$ value of 0.00 and coefficient value of 0.61 .
\end{abstract}

Keywords: cognitive, strategy and comprehension

\section{Introduction}

In this digital age, many forms of reading are exposed and can be accessed online or in print. The exposure of text that is very easily accessed in cyberspace in the form of electronic journals, e-books, online magazines makes it easy for students to explore knowledge. It is very abundant, and user can access it fast using internet. Millions of people around the world routinely access expository information from the internet written in English as second or foreign language for most users (Benhart; 2011: 19).

In the process of teaching and learning in higher education level, students must review many articles in order to gain more knowledge. At the end of their studies, they must produce scientific papers so that this activity has produced millions of scientific works each year. Scientific work also seems to have increased over the past decade, this can be seen from many international scientific events conducted in national or international levels. Most researchers or lecturers must present their new findings to the public to promote the development of scientific work. Related to this phenomenon, reading activities have an important role in getting and sharing information. This is in line with Grabe (2009: 15) who views reading as the most important skill needed by people in multicultural and international environments, academic learning, and independent learning situations. For example, there are many events in a multicultural environment that have been written in the form of magazines or booklets. 
Reading is a language skill that brings input to students and so they can explore many references to their studies. In these circumstances, reading becomes a language skill that is very urgent for students. Reading is the most important skill in gaining knowledge for their students (Safdarian, et.al., 2014: 121). Students will find many solutions in gaining knowledge more easily, they can reconstruct what they have obtained in different languages. By reading more scientific texts, they will easily re-express ideas into well-structured written text. In addition, reading also aims to get theories, main ideas and conclusions. Likewise, by reading it is expected that the reader will get information, find the essence of the text, and integrate information obtained from various reading sources, criticize the text and general understanding (Grabe; 2009: 15). Other reading functions are for exams and improve students' self competence.

In the reading process, "understanding the message requires withdrawing information from the message and the internal scheme until the set is reconciled as a single scheme or message" (Anderson et al. In Hudson 1982: 187). The process of reading, therefore, involves identifying genre, formal structure and topic, all of which activate the scheme and enable the reader to understand the text (Swales 1990: 89). Related to this, it is assumed that the reader not only has all the appropriate schemes, but this scheme is actually activated. In the process of reading, some understanding problems can occur. It is likely that there will never be a total coincidence of the scheme between the writer and the reader (Wallace 1992: 82). This current article focused on exploring the correlation between students' cognitive reading strategies and reading performance. It is intended to enrich the discussion of reading strategies in more detail which contribute to the reading performance of EFL students.

\section{Related Literatures}

Reading comprehension is a complex cognitive ability providing the ability to integrate text information with the background knowledge of the reader and resulting in the explanation of a mental representation (Meneghetti, Carretti, \& De Beni, 2006 in Ahmadi et al, 2013:236). Reading comprehension requires many skills such as vocabulary knowledge, background knowledge, knowledge of grammar, metacognitive awareness, syntactic knowledge, and reading strategies (Grabe, 2009; Koda, 2007). Grabe (2009) also states that reading comprehension involves abilities to recognize words rapidly and efficiently, develop and use a very large recognition vocabulary, process sentences in order to build comprehension, engage a range of strategic processes and underlying cognitive skills. Klinger (2007:16) states that reading comprehension is a multicomponent, highly complex process that involves many interactions between readers and what they bring to the text (previous knowledge, strategy use) as well as variables related to the text itself (interest in text, understanding of text types).

Cognitive strategies include direct interaction with the task and help to facilitate comprehension, act directly on incoming information, manipulating it in ways that improve learning. Cognitive strategies can be divided as the following elements: recognizing, using topics, guessing from the context, using a dictionary, writing down, imagery, activating background information, summarizing, using linguistic clues, using text markers, skipping the difficult parts' and repeating words or phrases. In other words, metacognitive reading strategies are higher order performance methods that refer to the planning, monitoring, and evaluating the success of a learning activity (Pressley \& Afflerbach, 1995 in Ahmadi et al, 2013:236). Van Dijk and Kintsch (1983) identified many types of strategies used for different cognitive tasks. These strategies include language strategies, grammatical strategies, discourse strategies, cultural strategies, social strategies, interactional strategies, pragmatic 
strategies, semantic strategies, schematic strategies, and stylistic and rhetorical strategies. They further delineated specific strategies involved in comprehension, including sociocultural strategies, communicative strategies, general reading strategies, local comprehension strategies, local coherence strategies, schematic strategies and knowledge use strategies.

Reading comprehension is a cognitive ability that provides the ability to synchronize text information with background knowledge that can produce mental explanations (Meneghetti, Carretti, \& De Beni, 2006 in Ahmadi et al, 2013: 236). Reading comprehension must also be equipped with many skills such as vocabulary knowledge, background knowledge, grammar knowledge, metacognitive awareness, syntactic knowledge, and reading strategies (Grabe, 2009; Koda, 2007). Grabe (2009) also states that the reading needs to consider the meaning of words quickly and efficiently, and the uses of vocabulary, the process of sentence preparation in building understanding, and the underlying cognitive skills. Reading comprehension is a very complex process and involves a lot of interaction between the reader and prior knowledge, the use of strategies (Klinger, 2007: 16)

Van Dijk and Kintsch (1983) stated that many types of strategies used for different cognitive tasks. These strategies include language strategies, grammatical strategies, discourse strategies, cultural strategies, social strategies, interactional strategies, pragmatic strategies, semantic strategies, schematic strategies, and style and rhetoric strategies. Cognitive strategies can be divided as elements that are followed: discussing, using topics, guessing from context, using dictionaries, writing, imaging, activating background information, summarizing, using linguistic cues, using text markers, connecting difficult parts' and repeating words or phrase.

\section{Method}

The current research is quantitative in nature. The quantitative is intended to describe the responses of EFL learners to cognitive and reading strategies and to explain to what extent the correlation between students' cognitive reading strategies and reading comprehension. The samples are the fourth semester students of English education as subjects or participants of the research. Data were collected by distributing questionnaires to get responses from students in term of Cognitive Reading Strategies. Reading Comprehension Test using IELTS Reading Testing was used to get Students' reading comprehension scores. The quantitative data were analyzed by correlation product moment.

\section{Results}

The findings of this research are based on the research questions consisting of description of reading strategies applied by students and the scores of reading performance.

\section{Cognitive Reading Strategies}

Majority of EFL students or 31 respondents are skimming the text quickly to get the gist. It means that skimming is very familiar strategy and most of EFL students like skimming when they are starting to read the text. Most of respondents or 23 students respondents usually guess the meaning of a word from the context. 
Picture 1. Distribution of participants' responses toward Skimming the text quickly to get the gist.

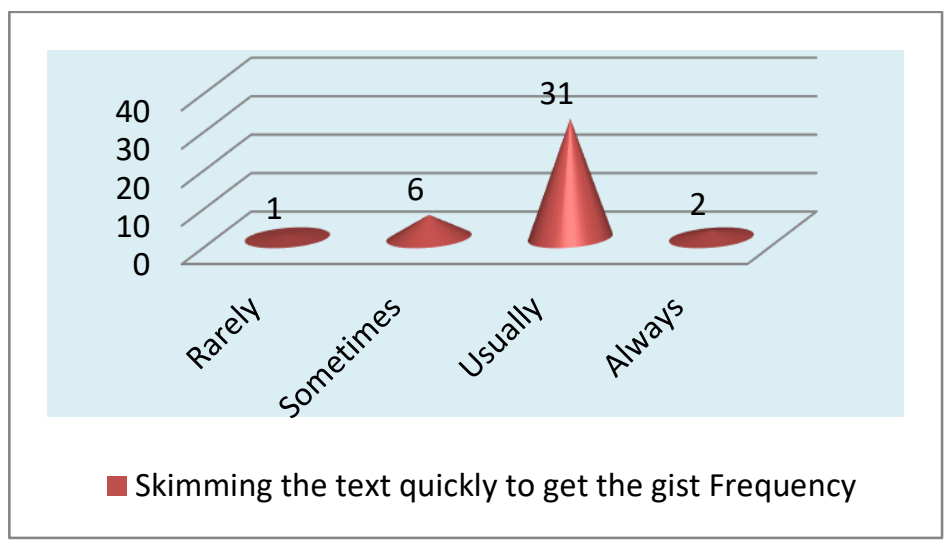

Source: Primary Data

Picture 2. Distribution of participants' responses toward Guessing the meaning of a word from the context.

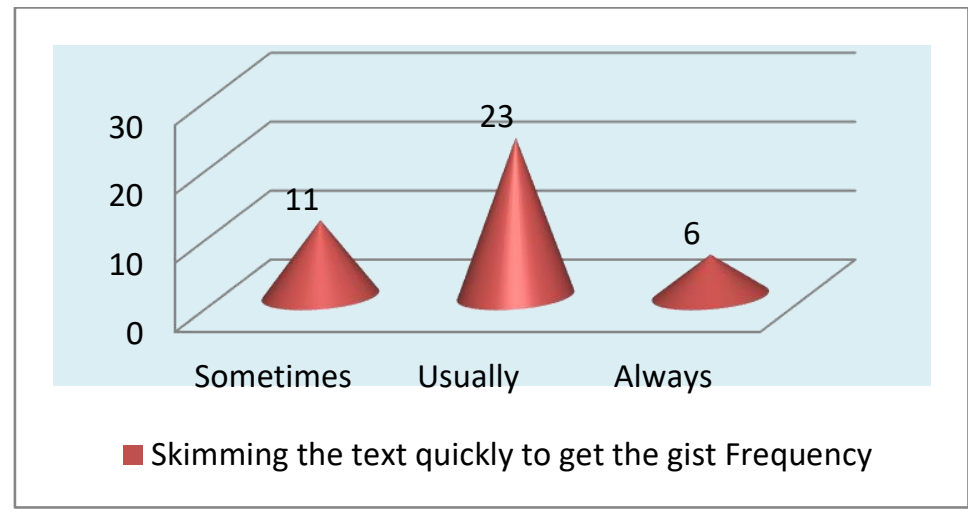

Source: Primary Data

Picture 3. Distribution of participants' responses toward Taking notes on the important points of the text.

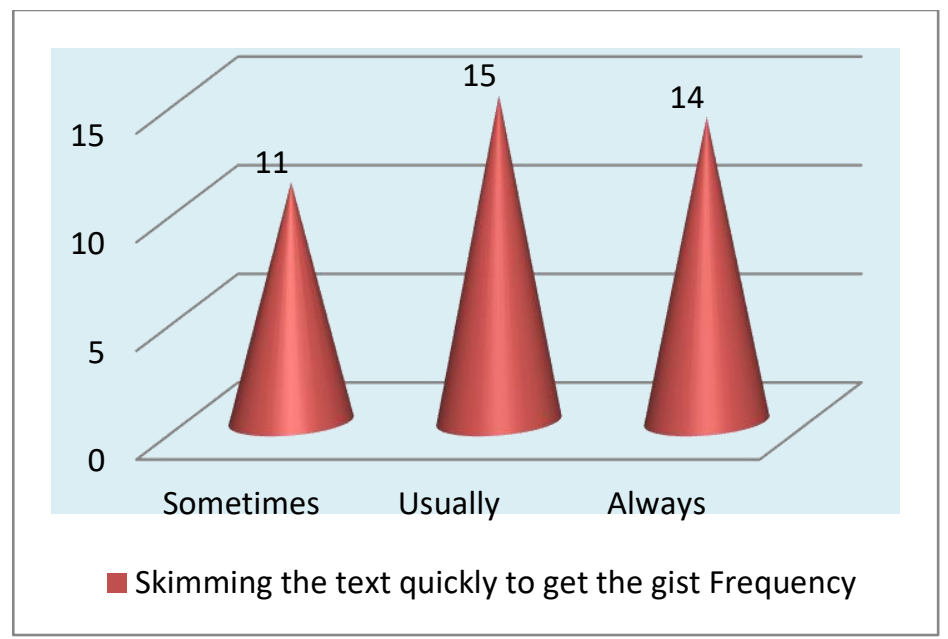

Source: Primary Data

Taking notes on the important points of the text is an important or needed reading strategy for students. This is proven by the finding above that shows the 15 respondents usually conduct it and 14 respondents always take notes on the important of the text. 
Picture 4. Distribution of participants' responses toward Relating the text to background knowledge about the topic to remember important information.

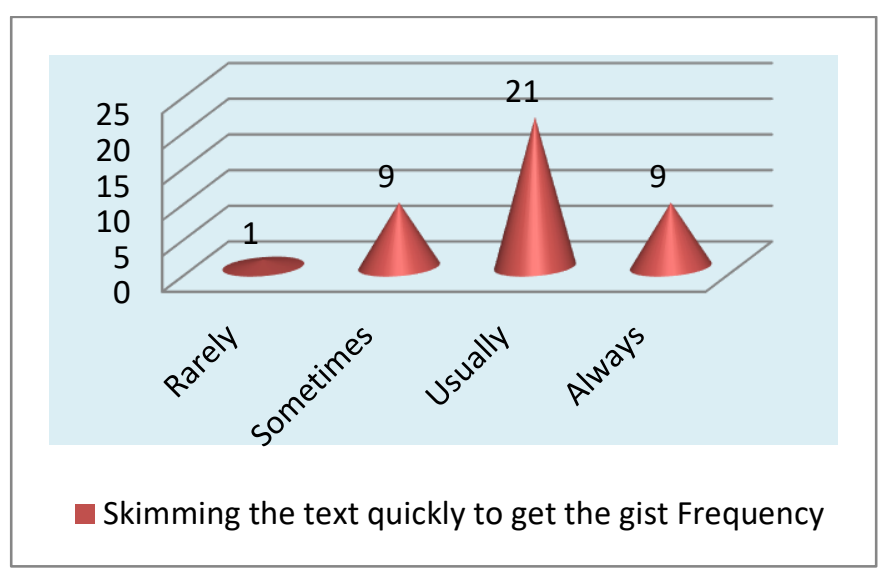

Source: Primary Data

Majority of students or 21 of respondents usually relate the text to background knowledge about the topic to remember important information.

\section{Reading Comprehension Scores of EFL Students.}

Table 1. Reading Comprehension Scores of EFL Students.

\begin{tabular}{|c|c|c|c|}
\hline Students & $\begin{array}{c}\text { Reading } \\
\text { Comprehension }\end{array}$ & Students & $\begin{array}{c}\text { Reading } \\
\text { Comprehension }\end{array}$ \\
\hline 1 & 62,5 & 21 & 80 \\
\hline 2 & 70 & 22 & 80 \\
\hline 3 & 62,3 & 23 & 80 \\
\hline 4 & 57,5 & 24 & 80 \\
\hline 5 & 60 & 25 & 82,5 \\
\hline 6 & 80 & 26 & 62,5 \\
\hline 7 & 60 & 27 & 62,5 \\
\hline 8 & 62,5 & 28 & 85 \\
\hline 9 & 65 & 29 & 87,5 \\
\hline 10 & 70 & 30 & 80 \\
\hline 11 & 80 & 31 & 62,5 \\
\hline 12 & 80 & 32 & 65 \\
\hline 13 & 90 & 33 & 80 \\
\hline 14 & 90 & 34 & 67,5 \\
\hline 15 & 87,5 & 35 & 67,5 \\
\hline 16 & 80 & 36 & 70 \\
\hline 17 & 80 & 37 & 72,5 \\
\hline 18 & 80 & 38 & 72,5 \\
\hline 19 & 80 & 39 & 87,5 \\
\hline 20 & 72,5 & 40 & 72,5 \\
\hline
\end{tabular}

The results of this research show that the highest of reading comprehension is 90 and the lowest is 62.5 . 


\section{Correlation between Students' Cognitive Reading Strategies and Reading Comprehension}

After analyzing the data from questionnaires and students' reading comprehension scores, researcher found that cognitive reading strategies correlate significantly to EFL students' reading comprehension with $p$ value: 0.00 . This is under 0.05 in which statistically all of reading strategies correlate significantly to reading comprehension as stated in the Table 2 below.

Table 2. Correlation between Cognitive Strategies and EFL Students' reading Performance

\begin{tabular}{|ll|r|r|}
\hline & & $\begin{array}{r}\text { Cognitive Reading } \\
\text { Strategy }\end{array}$ & $\begin{array}{r}\text { Reading } \\
\text { Comprehension }\end{array}$ \\
\hline \multirow{3}{*}{ Cognitive Reading Strategy } & Pearson Correlation & 1 & $.608^{* *}$ \\
& Sig. (2-tailed) & & .000 \\
& $\mathrm{~N}$ & 40 & 40 \\
& Pearson Correlation & $.608^{* *}$ & 1 \\
Reading Comprehension & Sig. (2-tailed) & .000 & \\
& $\mathrm{~N}$ & 40 & 40 \\
\hline \multirow{*}{**}{. Correlation is significant at the 0.01 level (2-tailed). }
\end{tabular}

Source: Analyzed Data

These cognitive reading strategies are important for students to know and should be applied in reading process. Based on the finding of this current research, students' cognitive reading strategies significantly correlate to their reading comprehension. After analyzing partially, the correlation between cognitive reading strategies and reading performance is $61 \%$ with $p$ value 0.00 .

\section{Discussion}

Reading is an important language skill, because reading will deliver a learner to get much information from the texts. Reading is a process in getting meaning or making meaning through many activities before, while and after reading the text. The application of cognitive reading strategies is a must because these strategies have contributed to EFL students' reading comprehension. Cognitive reading comprehension is an important factor as determinant EFL students' reading comprehension. Because cognitive strategy is a mental routine or procedure for accomplishing a cognitive goal. As Van Dijk and Kintsch (1983: 68) describe that thinking and problem solving are well-known examples: We have an explicit goal to be reached, the solution of a problem, and there may be specific operations, mental steps, to be performed to reach that goal. These steps are under our conscious control and we may be at least partly able to verbalize them, so that we can analyze the strategies followed in solving the problem. So cognitively, mental steps should be performed by a reader under conscious control to reach the goal of reading. Here is the important role of cognitive reading strategies that direct and facilitate a learner to comprehend the content of the text.

From many cognitive strategies, the current study only takes four strategies including: 1). Skimming the text quickly to get the gist, 2). Guessing the meaning of a word from the context. 3). Taking notes on the important points of the text, 4). Relating the text to background knowledge about the topic to remember important information. After testing with correlation, the results show that the cognitive strategies of students are positively correlated to reading comprehension. This shows that the cognitive strategies are very important in taking meaning in the reading process. The result of taking meaning is the student's level of 
understanding. As Van Dijk and Kintsch (1983: 68) explain, thinking and solving problems are well-known examples: We have explicit goals to be achieved, solutions to a problem, and there may be special operations, mental steps, that must be carried out to achieve goals that. The important thing is that cognitively, mental steps must be taken by the reader under conscious control to achieve the reading goal. As stated above (in introduction) that reading comprehension is a complex cognitive ability providing the ability to integrate text information with the background knowledge of the reader and resulting in the explanation of a mental representation (Meneghetti, Carretti, \& De Beni, 2006 in Ahmadi et al, 2013:236). Reading comprehension requires many skills such as vocabulary knowledge, background knowledge, knowledge of grammar, metacognitive awareness, syntactic knowledge, and reading strategies (Grabe, 2009; Koda, 2007).

This study also supports some previous research including Nergis (2013) who studied the reading comprehension of EFL students and the determinant variables support the findings of this study. He applied multiple regression to analyze the data to find out what factors influenced the reading comprehension of EFL students. She applies multiple regression to analyze her data to know what factors affecting EFL students' reading comprehension. She states that first language (L1) background students, depth of vocabulary knowledge, syntactic awareness, and metacognitive reading strategies are the predictors of academic reading comprehension for English for Academic Purposes (EAP) students. Fotovatian \& Shokrpour (2014) compares three categories of reading comprehension strategies (metacognitive, cognitive, and socio-affective) to determine their effects on $31 \mathrm{EFL}$ students' reading comprehension. A standard reading comprehension test taken from the First Certificate in English (FCE) and a questionnaire were used to collect the data. The results of the analysis using Chi-square tests revealed that cognitive strategies have positive effects on reading comprehension.

\section{Conclusion}

The conclusion of this current research can be drawn from the finding above that is cognitive reading strategies correlate significantly to students' reading comprehension. The application of cognitive reading strategies is a must because this strategy has contributed to students' reading comprehension. Cognitive reading strategies are important factors in determining students' reading comprehension. Because they are mental routines or procedures to achieve cognitive goals. Based on the finding, this article suggests for some items that are as follows: 1) cognitive reading strategies should be taught in the classroom intensively to improve EFL reading skill and their reading comprehension; 2) For policy makers, it is important to consider cognitive reading strategies, especially for developing reading curriculum for higher level education students, because reading is very important skill in getting information or knowledge.

\section{References}

Ahmadi, M. R., \& Pourhossein, A. G. (2012). Reciprocal teaching strategies and Their Impacts on English Reading Comprehension. Theory and Practice in Language Studies, 2(10), 2053-2060.

Benhart, E. B. (2011). Understanding advanced second-language reading. London: Routledge.

Fotovatian, S. \& Shokrpour, N. (2014). Comparison of the Efficiency of Reading Comprehension Strategies on Iranian University Students' Comprehension. Journal of College Reading and Learning, 37(2), 47-63. 
Grabe, W. (2009). Reading in a second language: Moving from theory to practice.

Hudson, T. (2007). Teaching Second Language Reading. Oxford: Oxford University Press.

Klinger, J. K. et al. (2007). Teaching Reading Comprehension to Students With Learning Difficulties. New York, NY: The Guilford Press A Division of Guilford Publications, Inc.

Koda, K. (2007). Reading and Language Learning: Crosslinguistic Constraints on Second Language Reading Development. Language Learning, 57(1), 1-44.

Nergis, A. (2013). Exploring the factors that affect reading comprehension of EAP students. Journal of English for Academic Purposes, 12, 1-9.

Pressley, M. (2000). What should comprehension instruction be the instruction of? English Language Teaching, 6(10).

Safdarian, Z., et al. (2014). How Reading Strategy Use And Personality Types Are Related?. The Reading Matrix, 14(1). 